\title{
Three-phase Bidirectional Battery Charger for Smart Electric Vehicles
}

\author{
J. Gallardo-Lozano, M. I. Milanés-Montero, M. A. Guerrero-Martínez, E. Romero-Cadaval \\ Power Electrical and Electronic Systems (PE\&ES), School of Industrial Engineering \\ (University of Extremadura), (http://peandes.unex.es)
}

\begin{abstract}
A three-phase battery charger for electric vehicles is proposed in this paper. The charger is bidirectional, allowing the Charging and Vehicle to Grid operation modes. A novel Balanced Sinusoidal Source Current control strategy is proposed so that the charger demands or injects into the grid a perfect sinusoidal and balanced source current in phase with the positive sequence fundamental component of the phase-toneutral grid voltage, achieving a unity displacement power factor. In this way, the charger turns the car into a smart vehicle, reducing the existing problem of harmonic current demand by electric and hybrid vehicles and improving the power quality of the electric power system. The topology and control stage of the charger are shown. Simulation tests are conducted to validate the proper operation of the charger under sinusoidal, distorted and unbalanced source voltages.
\end{abstract}

\section{INTRODUCTION}

Hybrid Electric Vehicles (HEV) and Electric Vehicles (EV) are becoming more and more attractive due to the higher oil prices and the development of new battery technologies, such as Lithium-Ion, which have higher power and energy density. The battery charger converts the alternating current distributed by electric utilities into the direct current needed to recharge the battery. This mode of operation is known as Grid to Vehicle (G2V). However, a Vehicle to Grid (V2G) concept has arisen in the last years, allowing returning back to the grid the energy stored in the battery packs that has not been used by the vehicle. This operation mode will cause a great impact on the power grid. Specifications for V2G technology are still being developed by the Society of Automotive Engineers as part of the ZigBee Alliance [1]-[3].

At present there are commercial EVs with single-phase unidirectional G2V chargers, which demand a highly distorted current form the grid. As an example, the measured current demanded by a commercial car (Reva-i) while charging the battery is shown in Fig. 1(a) and the harmonic spectrum is displayed in Fig. 1(b). The Total Harmonic Distortion (THD) of the demanded current is over 20\%, far exceeding the value permitted by the standard IEEE-519. If a proliferation of EVs is expected in the next years, it is very important to investigate in the control strategies of chargers in order to reduce the harmonic distortion demanded by the batteries or the power grid will suffer a power quality degradation.

Besides, the time required to recharge electric vehicle batteries depends on the total amount of energy that can be

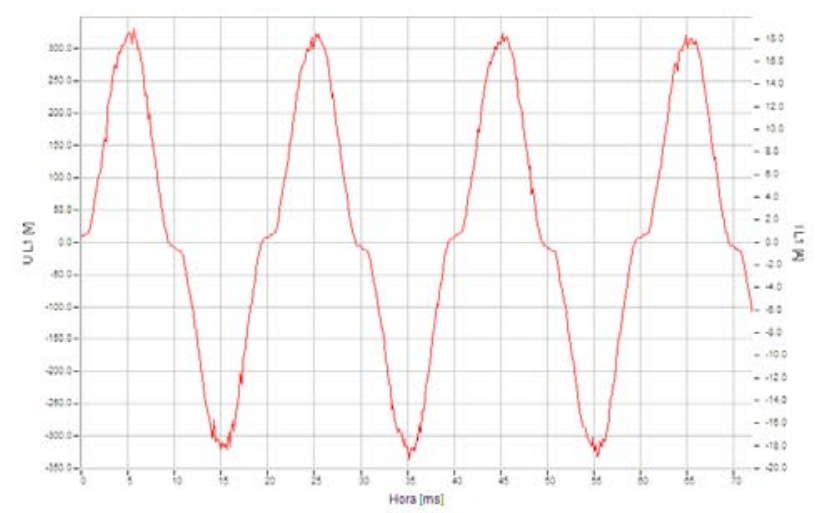

a)

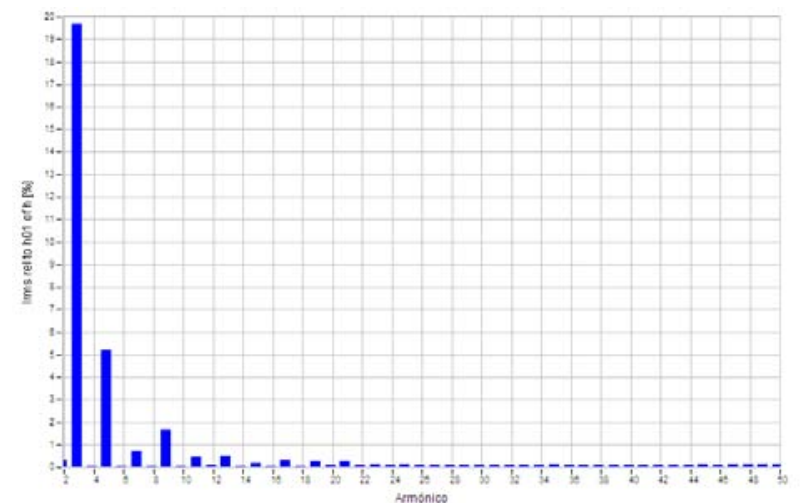

b)

Fig. 1. Demanded current to the grid by the electric vehicle Reva-I when charging the battery. (a) Waveform of the demanded current; (b) Spectrum of the demanded current (THDI = 20,475\%).

stored in the battery pack, and the power available from the battery charger. According to it, the design of three-phase chargers will allow, on the one hand, managing a higher power flow between the battery and the grid and, on the other hand, providing or demanding power to help balance loads. Nowadays, a great study of charger models is being carried out [4]-[11].

In this paper a three-phase bidirectional (G2V and V2G operation modes) battery charger is presented. The novel control strategy proposed for the charger turns the car into a smart vehicle, demanding or injecting a sinusoidal and balanced source current, with unity displacement power factor, contributing to the improvement of the power quality. Simulation models of the battery pack, including the selfdischarge effect, and the charger have been implemented to 
validate by simulation the proper operation of the charger under sinusoidal, distorted and unbalanced source voltages.

\section{BATTERY MODEL}

Some battery models have been implemented to be able to simulate the battery behavior in HEVs and EVs [12]. In general, existing battery models can be classified in three main types [13]: experimental, analytical and electric circuitbased models. The first type uses differential equations to simulate the complex electrical-chemical process in a battery [14] so, it requires intensive computations to solve the interdependent partial differential equations and they are difficult to be configured and used [15]. Analytical models simulate an equivalent mathematical representation to approximate the battery performance [16]-[18], but they ignore circuit features (voltage and internal resistance). Electric circuit-based models are useful to represent electrical characteristics of batteries [19]-[21].

According to it, an electric circuit-based model has been used for the battery model. A novelty in this model is the inclusion of the self-discharge effect, as it is an important parameter since cars can be parked for very long time. A controlled voltage source (modelled with a non-linear equation) in series with a constant resistance [19] is used to simulate the behavior of Lead-Acid, Lithium-Ion (Li-Ion) and Nickel-Metal-Hydride (NiMH) batteries, as shown in Fig. 2.

A Simulink block is created to implement the battery model with one input (the current provided by the BMS) and two outputs: State-of-Charge (SOC) and voltage between the electrodes.

The parameters of the model are obtained from the manufacturer's discharge curve and electrical characteristics from the datasheet of the battery (Fig. 3). The battery used in the different simulations is implemented with eight modules of "MP 176065 Integration” of Saft Batteries. It is important to mention that it is assumed the same characteristics for the charge and the discharge cycles [19].

In Fig. 4, the input parameters mask in the battery model is shown.

In addition to represent the battery behavior during driving, cars can be parked and left for long time, so the battery model must have into account the self-discharge and a new block has been designed and inserted into the battery model to include this parameter. The self-discharge is measured as the percentage per month of reduced stored charge of the battery without any connection between the electrodes, so the proposed block adds to the input current an additional amount

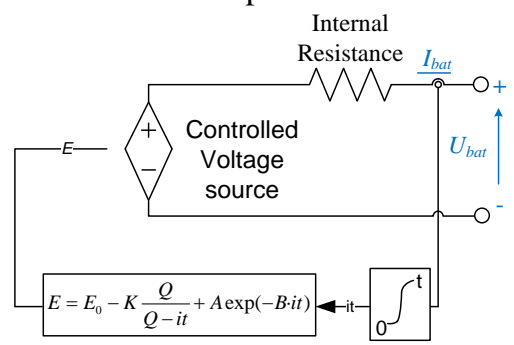

Fig. 2. Non-linear battery model.

\begin{tabular}{l} 
Electrical characteristics \\
Nominal voltage \\
(1.4 A rate at $20^{\circ} \mathrm{C}$ ) \\
\hline Typical capacity $20^{\circ} \mathrm{C}$ \\
[at $1.4 \mathrm{~A} 20^{\circ} \mathrm{C} 2.5 \mathrm{~V}$ cut-off] \\
\hline Nominal energy
\end{tabular}

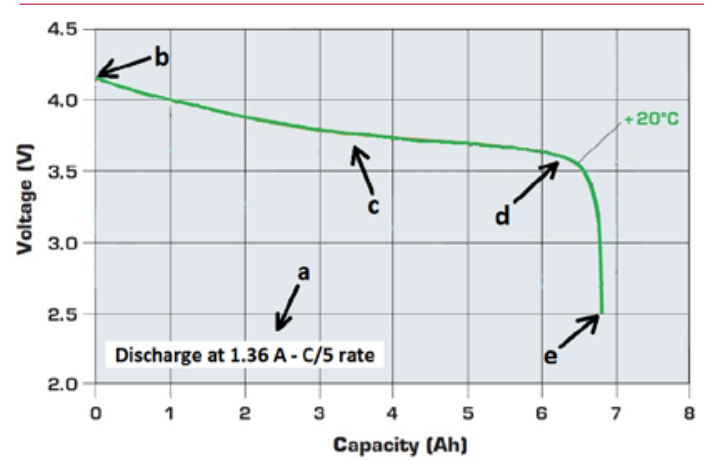

Fig. 3. Datasheet of the battery “MP 176065” of Saft Batteries.

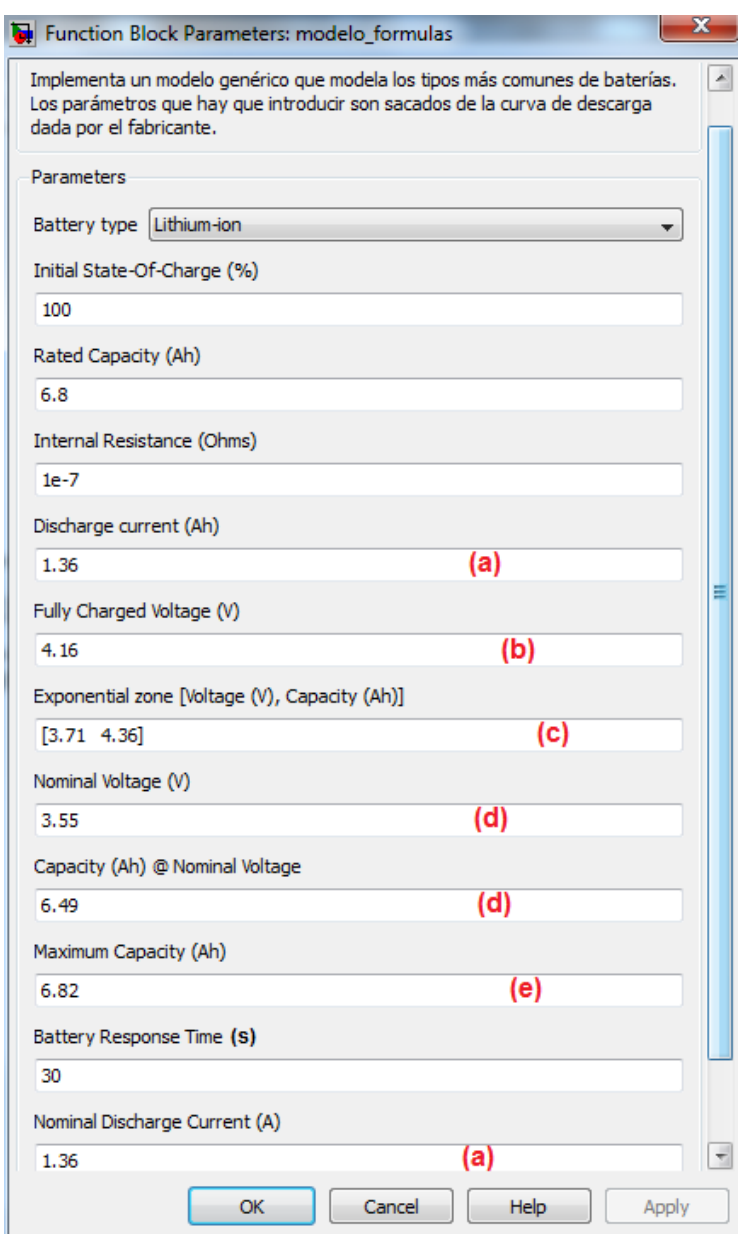

Fig. 4. Input parameters in the model for "MP 176065 Integration" of Saft.

that causes a battery discharge equivalent to the selfdischarge and it is implemented as shown in Fig. 5.

From Fig. 5, it can be seen that no connection between the electrodes is detected when the current is zero and no variation occurs, what implies that the derivative of the battery current is zero. This detection keeps in memory the value that the SOC had when the disconnection occurred and 


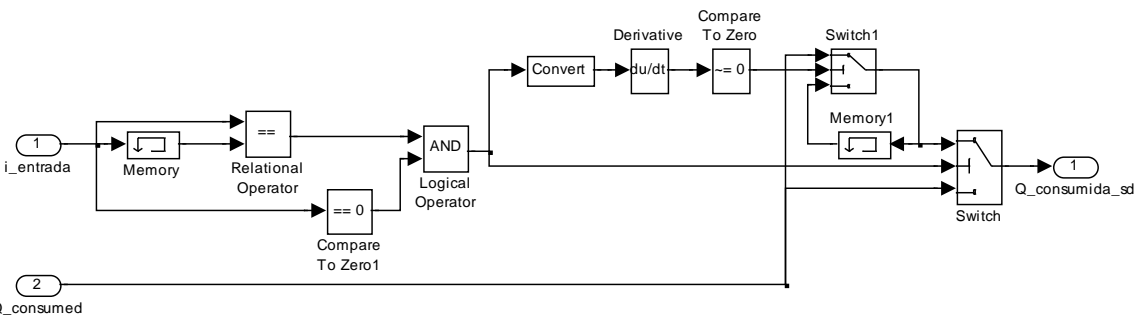

Fig. 5. Calculation of the battery self-discharge current.

calculates the amount of current needed to simulate the correct self-discharge.

A simulation has been implemented to check whether the self-discharge function works correctly (Fig. 6).

In Fig. 6, the battery model is shown with zero Amperes of reference input current, which simulates no connection between the electrodes. The instantaneous SOC and output voltage can be measured from the outputs of the model.

The initial SOC has been set to $100 \%$ and the selfdischarge have been set to $2.5 \%$. Attending to these values, in a period of a month, a drop of $2.5 \%$ (from $100 \%$ to $97.5 \%$ ) of the SOC is expected. The result is shown in Fig. 7.

\section{BIDIRECTIONAL BATTERY CHARGER}

\section{A. Topology}

A three-phase bidirectional battery charger is studied in this paper. This bidirectional charger has two power stages: stage 1 is a DC/DC bidirectional converter; stage 2 is a bidirectional inverter.

In Fig. 8, the topology of the proposed charger is shown. The aim of this topology is to charge the battery demanding energy from the grid (in case the vehicle is pretended to be driven in a near future) or to discharge it returning the energy into de grid (for instance, when the car is parked at peaks of

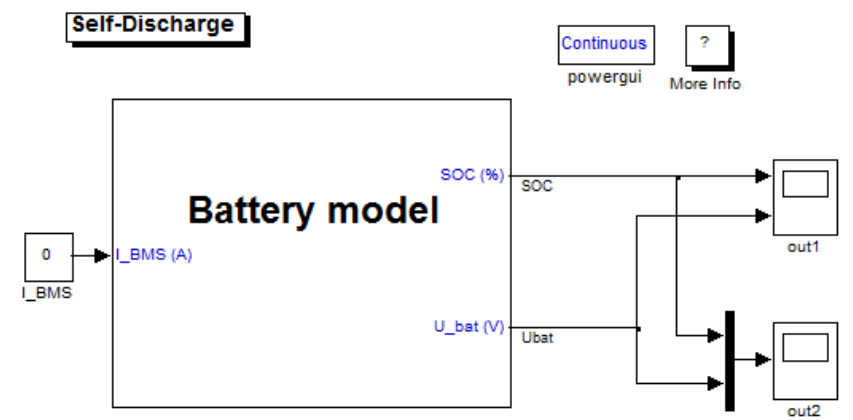

Fig. 6. Simulation to test the self-discharge function.
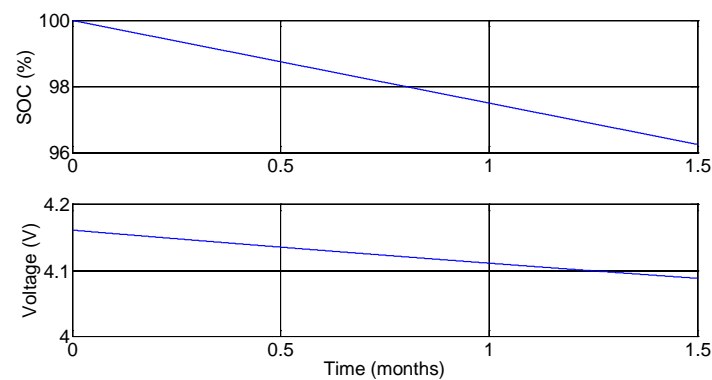

Fig. 7. Effect of the battery self-discharge.

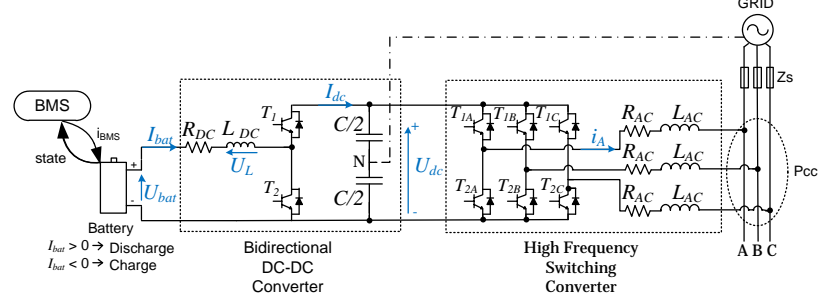

Fig. 8. General electric diagram of the bidirectional charger.

consumer energy demand to the grid).

The DC/DC converter is in charge of increasing the battery output voltage to the suitable inverter input voltage. In addition, the voltage in the inverter input is fixed to a constant level, independently of the voltage variation in the battery output due to its State-Of-Charge.

On one hand, the bidirectional inverter performs the function of converting the DC values (from the DC/DC converter) to the suitable AC values in order to inject (or demand) sinusoidal currents in phase with the voltage into the grid. On the other hand, in case the battery is being charged, the inverter converts the $\mathrm{AC}$ values (from the grid) to the suitable constant DC values with which the DC/DC converter works.

The criterion to determine the charge or discharge of the battery is the direction of the current. Positive battery current corresponds to a discharge process (flow from battery towards the grid). Therefore, negative battery current corresponds to a charge process (flow from the grid towards the battery).

\section{B. DC/DC Bidirectional Converter}

It has two operating modes: a first charging mode, in which the current flow is from the battery towards the grid, and a second mode, the discharging one, where the current flows from the grid towards the battery [22].

\section{Bidirectional Inverter}

A three-phase three-leg topology with mid-point DC bus is used for the bidirectional inverter, as it is shown in Fig. 9. The mid-point of each leg is connected to the grid by a filter inductor with an internal resistance $R_{A C}$ and inductance $L_{A C}$, while the mid-point of the DC bus is connected with no impedance to the neutral conductor.

To carry out an analysis it is important to highlight the following points:

- It is needed a signal of control for each leg, that is to say, three signals of control, as its activation causes the activation of $S 1$ switches in each leg and the 


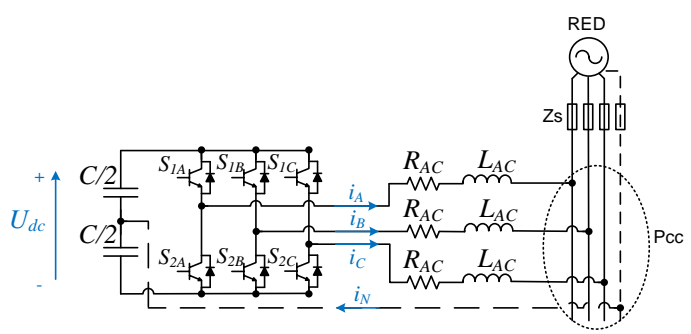

Fig. 9. Electric diagram of the three-phase inverter.

deactivation of $S 2$ switches (and vice versa). Each leg works with its own grid phase independently.

- It is necessary to satisfy

$$
U_{d c}>2 \cdot \hat{u}_{A N}
$$

where $U_{d c}$ is the DC inverter input voltage and $\hat{u}_{A N}$ is the peak value of the phase-neutral voltage (which is the maximum instantaneous value it can reach).

\section{CONTROL STRATEGIES}

The control strategies generate the reference currents for each converter.

\section{A. DC/DC Converter}

The DC/DC converter is controlled by the battery current, $I_{\text {bat }}$. The reference current value comes from the BMS:

$$
I_{b a t, r e f}=I_{B M S} .
$$

\section{B. Bidirectional Inverter}

The output instantaneous power is calculated by

$$
p(t)=u_{A N} i_{A}+u_{B N} i_{B}+u_{C N} i_{C},
$$

where $u_{A N}, u_{B N}$ and $u_{C N}$ and $i_{A}, i_{B}$ and $i_{C}$ are the output voltaje and current in each leg in the ac side, respectively.

A novel Balanced Sinusoidal Source Current (BSSC) control strategy is proposed. The objective is that the charger injects (or demand) into the grid a current without harmonics, in phase with the positive sequence fundamental component of the phase-to-neutral grid voltage, attaining a unity displacement power factor.

The inverter reference currents, $i_{i n v, r e f}$, are obtained multiplying a constant, $K$, by the unit vector of the positive sequence fundamental component of the phase-to-neutral grid voltage, as shown in

$$
i_{i n v, r e f}=K \cdot \vec{u}_{s_{1}}^{+}=\frac{P_{s}}{\left|u_{s_{1}}^{+}\right|} \vec{u}_{s_{1}}^{+},
$$

where $P_{s}$ is the three-phase active power injected or demanded from the grid, $\vec{u}_{s_{1}}{ }^{+}$is unit vector of the positive sequence fundamental component of the phase-neutral grid voltage and $\left|u_{s_{1}}{ }^{+}\right|$is its module.

The unit vector is calculated as

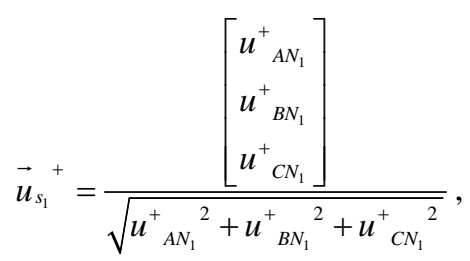

where $u^{+}{ }_{A N_{1}}, u_{B N_{1}}^{+}$and $u_{C N_{1}}^{+}$are the instantaneous positive sequence fundamental components of the phaseneutral grid voltage.

According to (5), equation (4) can be solved as shown in

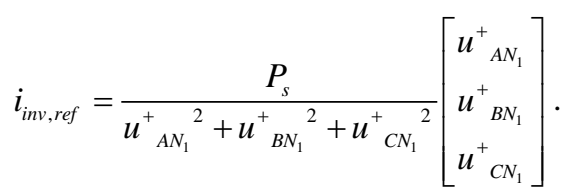

The inverter output power is equal to the inverter input power, so

$$
P_{s}=\overline{U_{d c} \cdot I_{d c}},
$$

where $U_{d c}$ and $I_{d c}$ are the output voltage and current of the DC/DC converter (input voltage and current of the inverter), equation (6) is finally solved (and therefore, the inverter reference current obtained) as

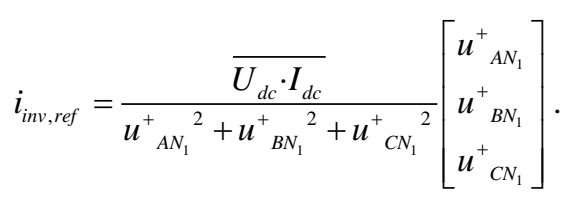

The block diagram of the control strategy of the inverter is displayed in Fig. 10. An Autoadjustable Synchronous Reference Frame (ASRF) has been used to obtain the positive sequence fundamental component of the grid voltage [23].

\section{TRACKING TECHNIQUES}

The switching signals of both converters are generated with a synchronous hysteresis band controller. At every sample time, the measured current is compared with the reference current, (2) or (8), depending on the converter.

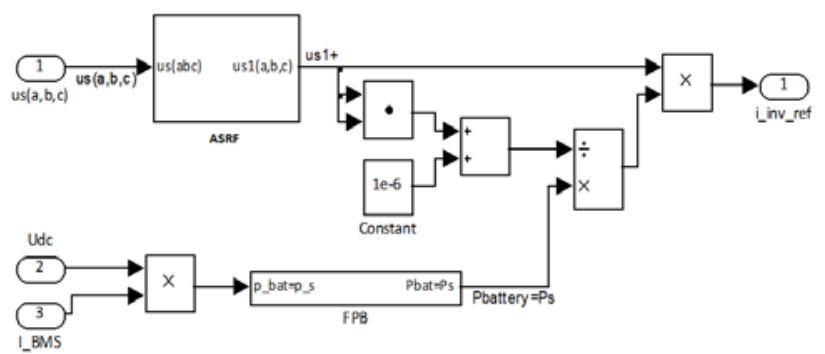

Fig. 10. Block diagram of the control strategy of the inverter. 


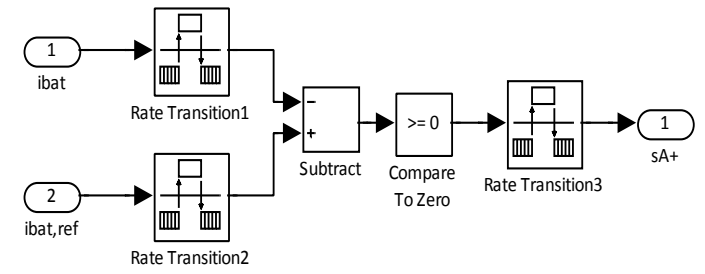

a)

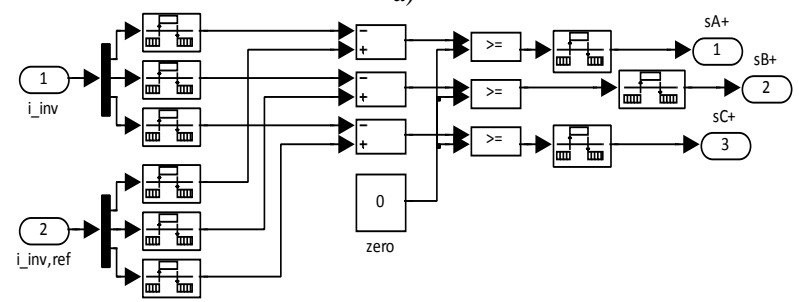

b)

Fig. 11. Block Diagram of the tracking technique for a) DC/DC Converter b) Phase A of the inverter.

The block diagram of the tracking technique for both converters is shown in Fig. 11.

\section{SIMULATION RESULTS}

The complete system simulated, using MATLAB-Simulink is shown in Fig. 12. The parameters values are summarized in Table I.

\section{Case 1: Sinusoidal source voltage}

a) Charge mode

In Fig. 13(a), the phase A of the grid voltage is shown in the upper subplot. In the lower subplot, the reference current and the real current demanded to the grid are displayed.

b) Discharge mode

In Fig. 13(b), the generation of the reference current and the measured current are shown for the discharging mode.

Fig. 13 shows that the reference current is correctly followed in both charge and discharge modes and the obtained $T H D_{\text {is }}$ is $8,1 \%$ and $9,4 \%$, respectively.

2. Case 2: Voltage source with harmonic distortion $H D v 3=20 \% \quad\left(3^{\text {rd }}\right.$ harmonic $) ; H D v 5=20 \% \quad\left(5^{\text {th }}\right.$ harmonic)

In this case, harmonic distortion is included in the grid voltage. It allows to check the performance of the charger when the mains present disturbances. As the reference current
TABLE I

PARAMETERS OF THE SIMULATION MODEL

\begin{tabular}{|c|c|}
\hline RMS grid voltage & $230 \mathrm{~V}$ \\
\hline Grid frequency & $50 \mathrm{~Hz}$ \\
\hline$U_{d c}$ & $1380 \mathrm{~V}$ \\
\hline$L_{D C}=L_{A C}$ & $50 \mathrm{mH}$ \\
\hline$R_{D C}=R_{A C}$ & $5 \Omega$ \\
\hline$I \_B M S$ & $10 \mathrm{~A}$ \\
\hline
\end{tabular}

is obtained from the voltage positive sequence fundamental component, no harmonic distortion will affect the reference current generation. To carry out the simulation, the parameters remain equal as in Case 1 . The generation of the reference and measured currents are shown for

a) Charge mode: in Fig. 14(a).

b) Discharge mode: in Fig. 14(b).

The effect of harmonic distortion can be seen in the voltage (upper subplot in Fig: 14(a) and Fig. 14(b)). The lower subplots show that the reference current generated is sinusoidal without harmonic distortion and it is correctly followed. The obtained $T H D_{i s}$ for both the charge and discharge mode is $8,4 \%$ and $8,6 \%$, respectively.

3. Case3: Voltage source with imbalance (zero sequence and negative sequence of the fundamental component: 20\%)

The performance of the charger is checked under unbalanced grid voltage conditions. No disturbances will affect the reference current generation. The generation of the reference and measured currents are shown for

a) Charge mode: in Fig. 15(a).

b) Discharge mode: in Fig. 15(b).

The effect of imbalance can be seen in the voltage (upper subplot in Fig: 15(a) and Fig. 15(b)). The lower subplots in Fig. 15 show that the reference current generated is sinusoidal without imbalance and it is correctly followed. The obtained $T H D_{\text {is }}$ for both the charge and discharge mode is $8,4 \%$ and $8,6 \%$, respectively.

\section{CONCLUSIONS}

A three-phase bidirectional battery charger for electric vehicles has been presented in this paper. The charger operates with a novel Balanced Sinusoidal Source Current control strategy, demanding or injecting into the grid a balanced and sinusoidal current, making the car to become a

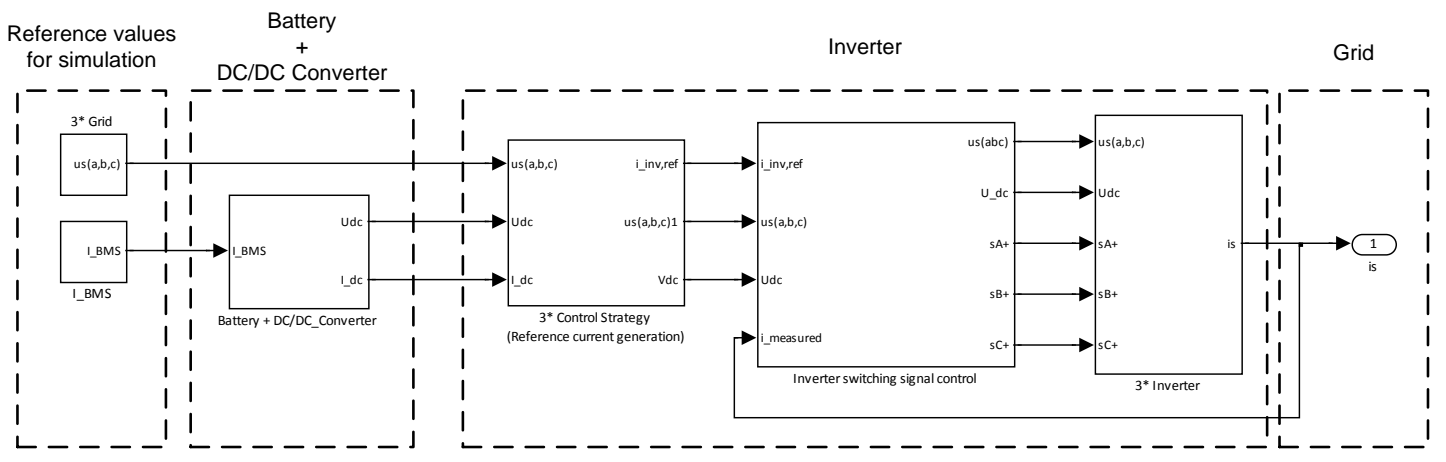

Fig. 12. Block diagram of the control strategy of the inverter. 

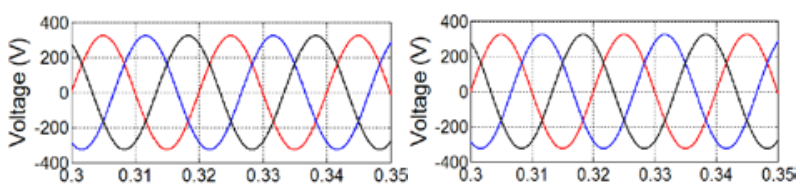

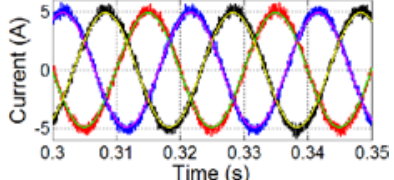

a)

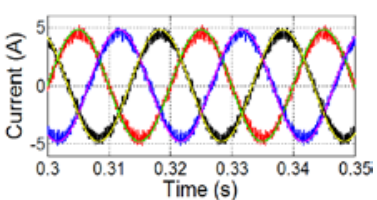

b)
Fig. 13. Evolution of the ideal voltage and the current into the bidirectional inverter's output during (a) battery's charge (b) battery's discharge.
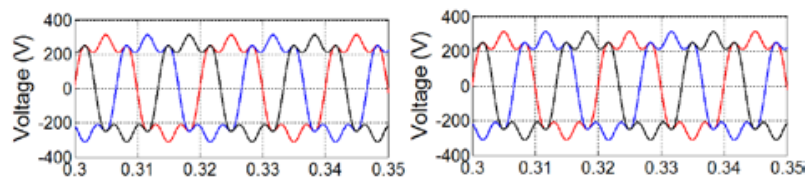

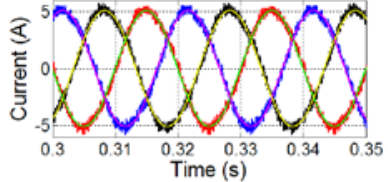

a)

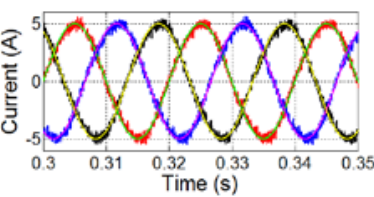

Fig. 14. Evolution of the distorted voltage and the current into the bidirectional inverter's output during (a) battery's charge (b) battery's discharge.
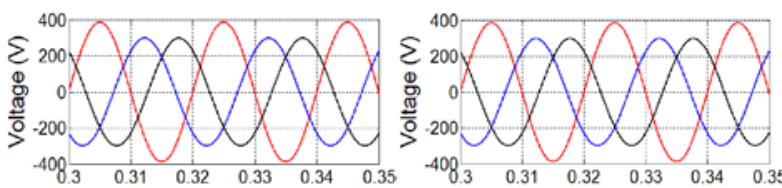

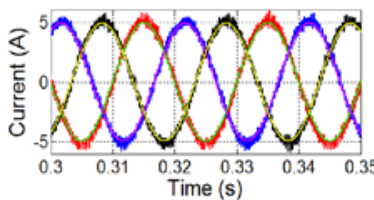

a)

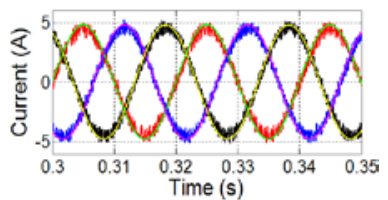

b)
Fig. 15. Evolution of the unbalanced voltage and the current into the bidirectional inverter's output during (a) battery's charge (b) battery's discharge.

smart vehicle contributing to the so-called Smart Grid. Simulation results under ideal and disturbed source voltages are presented to test the operation of the proposed charger.

\section{ACKNOWLEDGMENT}

This work was supported by the Spanish Ministry of Science and Innovation under the research project PSE-370000-2009-22, co-financed by FEDER.

\section{REFERENCES}

[1] M. El Chehaly, O. Saadeh, C. Martinez, G. Joos, “Advantages and applications of vehicle to grid mode of operation in plug-in hybrid electric vehicles”. Electrical Power \& Energy Conference, pp. 1-6. Oct. 2009.

[2] Sikai Huang, D. Infield, "The potential of domestic electric vehicles to contribute to Power System Operation through vehicle to grid technology”. Universities Power Engineering Conference, pp. 1-5. Sep. 2009

[3] Y. Ota, H. Taniguchi, T. Nakajima, K.M. Liyanage, A. Yokoyama, “An
Autonomous Distributed Vehicle-to-Grid Control of Grid-Connected Electric Vehicle”. Industrial and Information Systems, pp. 414-418. Dec. 2009.

[4] K. H. Chao, P. Y. Chen, C. H. Cheng, “A Three-Level Converter with Output Voltage Control for High-Speed Railway Tractions”, IEEE Conference of Industrial Electronics Society, pp. 1793-1798, Nov. 2007.

[5] S. Jaganathan, W. Gao, "Battery Charging Power Electronics Converter and Control for Plug-in Hybrid Electric Vehicle”, IEEE Conference Vehicle Power and propulsion, pp. 440-447, Sep. 2009.

[6] I. Cvetkovic, T. Thacker, D. Dong; G. Francis, V. Podosinov, D. Boroyevich, F. Wang, R. Burgos, G. Skutt, J. Lesko, "Future Home Uninterruptible Renewable Energy System with Vehicle-to-Grid Technology”, IEEE Energy Conversion and Exposition, pp. 26752681, Sept. 2009.

[7] Lixin Tang; Gui-Jia Su. “A Low-Cost, Digitally-Controlled Charger for Plug-In Hybrid Electric Vehicles”, IEEE Energy Conversion Congress and Exposition, pp. 3923-3929, Sept, 2009.

[8] M. Kisacikoblu, B. Ozpineci, L. Tolbert, "Examination of a PHEV Bidirectional Charger System for V2G Reactive Power Compensation”, IEEE Applied Power Electronics Conference and Exposition, pp. 458465, Feb. 2010.

[9] X. Zhou, S. Lukic, S. Bhattacharya, A. Huang, "Design and Control of Grid-connected Converter in Bi-directional Battery Charger for Plug-in Hybrid Electric Vehicle Application", IEEE Vehicle Power and Propulsion Conference, pp. 1716-1721, Sept. 2009.

[10] X. Zhou, G. Wang, S. Lukic, S. Bhattacharya, A. Huang, "MultiFunction Bi-directional Battery Charger for Plug-in Hybrid Electric Vehicle Application”, IEEE Energy Conversion Congress and Exposition, pp. 3930-3936, Sept. 2009.

[11] Y. J. Lee, A. Khaligh, A. Emadi, “Advanced Integrated Bidirectional AC/DC and DC/DC Converter for Plug-In Hybrid Electric Vehicles”, IEEE Journals Vehicular Technology, vol. 58, pp. 3970-3980, Oct. 2009.

[12] R. Rao, S. Vrudhula, D. Rakhmatov, "Battery Modeling for Energy Aware System Design”, Computer, vol. 36. NO. 12, pp. 77-87. Dec. 2003.

[13] J. Zhang, S. Ci, H. Sharif, M. Alahmad, “An Enhanced Circuit-Based Model for Single-Cell Battery”. Power Electronics Conference and Exposition (APEC) 2010 Twenty-fifth Annual IEEE, pp. 672-675. 2010.

[14] D. Rakhmatov, S. Vrudhula, D. A. Wallach, "A Model for Battery Lifetime Analysis for Organizing Applications on a Pocket Computer”. IEEE Journal Very Large Scale Integration (VLSI) Systems, vol. 11, issue 6, pp. 1019-1030, Dec. 2003.

[15] F. Cao, A. Charkey, K. Williams, "Thermal Behavior and End-Of-Life Characteristics of the Nickel-Zinc Battery". Energy Conversion Engineering Conference and Exhibit, 2000. (IECEC) 35th Intersociety, vol. 2, pp. 985-994, Jul. 2000.

[16] J. Newman, K. E. Thomas, H. Hafezi, D. R. Wheeler, "Modeling of Lithium-Ion Batteries”. Journal of Power Sources, pp. 838-843, 2003.

[17] P. Rong, M. Pedram, "An Analytical Model for Predicting the Remaining Battery Capacity of Lithium-Ion Batteries”, ”. IEEE Journal Very Large Scale Integration (VLSI) Systems,vol. 14, pp. 441-451, May 2006.

[18] M. Zheng, B. Qi, X. Du, "Dynamic Model for Characteristics of Li-Ion Battery on electric Vehicle”, 4th IEEE Conference Industrial Electronics and Applications, pp. 2867-2871, May 2009

[19] O. Tremblay, L. A. Dessaint, A. L. Dekkiche, “A Generic Battery Model for the Dynamic Simulation of Hybrid Electric Vehicles”, IEEE Conference Vehicle Power and Propulsion, pp. 284-289, Jun. 2008.

[20] R. Kroeze, P. Krein, "Electrical Battery Model for Use in Dynamic Electric Vehicle Simulations”, IEEE Conference Power Electronics Specialists, pp. 1336-1342, Aug. 2008.

[21] M. Chen, G. Rincón-Mora, “Accurate Electrical Battery Model Capable of Predicting Runtime and I-V Performance”, IEEE Journals Energy Conversion, vol. 21, issue 2, pp. 504-511, Jun. 2006.

[22] M. Ortúzar, J. Moreno, J. Dixon, "Implementation and Evaluation of an Ultracapacitor-Based Auxiliary Energy System for Electric Vehicles”, IEEE Transactions on Industrial Electronics, vol. 54, issue 4, pp. 21472156, Jul. 2007.

[23] M. Milanés-Montero, E. Romero-Cadaval, V. Miñambres-Marcos, F. Barrero-González, "Novel Method for Synchronization to Disturbed Three-Phase and Single-Phase Systems", IEEE International Symposium on Industrial Electronics. Jun. 2004. 